\title{
Photosensitization of A2E triggers telomere dysfunction and accelerates retinal pigment epithelium senescence
}

\author{
Jing Wang ${ }^{1,2}$, Yiji Feng ${ }^{1}$, Peng Han², Fenghua Wang ${ }^{1,3}$, Xueting Luo ${ }^{3,4}$, Jian Liang ${ }^{3,4}$, Xiangjun Sun ${ }^{5}$, Jing Ye ${ }^{2}$,
} Yiming $L u^{2}$ and Xiaodong Sun ${ }^{1,3,4}$

\begin{abstract}
Age-related macular degeneration (AMD) is the leading cause of irreversible vision loss in elderly people. AMD is classified as early, intermediate, advanced non-neovascular, and advanced neovascular forms depending on the clinical features. However, the exact pathogenesis remains unclear. Retinal pigment epithelium (RPE) cells degeneration is a hallmark of AMD. With aging, lipofuscin accumulates in RPE cells. N-retinylidene-Nretinylethanolamine (named A2E), a well-known fluorophore of lipofuscin, may contribute to RPE cells degeneration. In this study, we showed that photosensitization of A2E increased DNA damage, including telomere deprotection and deletion, and triggered cellular senescence. In addition, we found that the antioxidant $\mathrm{N}$-acetyl-cysteine (NAC) partially alleviated this DNA damage. Telomerase overexpression rescued A2E-mediated RPE cell senescence, indicating that telomere dysfunction plays an important role in A2E-based senescence. We further showed that the senescence induced by $A 2 E$ photosensitization may affect the microenvironment of the retina by expressing several factors of the secretory phenotype (SASP) including IL1B, IL13RA2, and CXCR4 through the NF-KB pathway. We propose that expression of these factors create a pro-inflammatory environment that drives retina degeneration. Moreover, our findings suggest that protecting telomeres is a valuable strategy for treating retinal degeneration diseases, such as AMD.
\end{abstract}

\section{Introduction}

Age-related macular degeneration (AMD) is the leading cause of irreversible vision loss in elderly people in the United States and other developed countries. It is estimated that by 2020 , nearly 80 million people will be affected by the disease ${ }^{1}$. The etiology of AMD is believed

\footnotetext{
Correspondence: Yiming Lu (luyiming@rjh.com.cn) or Xiaodong Sun (xdsun@sjtu.edu.cn)

${ }^{1}$ Department of Ophthalmology, Shanghai General Hospital (Shanghai First People's Hospital), Shanghai Jiao Tong University School of Medicine, No. 100 HaiNing Road, 200080 Shanghai, PR China

${ }^{2}$ International Laboratory in Hematology and Cancer (LIA), Shanghai Jiao Tong University School of Medicine/Ruijin Hospital/CNRS/INSERM/Nice University, Pôle Sino-Français de Recherche en Sciences du Vivant et Génomique, Shanghai Ruijin Hospital, Affiliated to Shanghai Jiaotong University, 200025 Shanghai, PR China

Full list of author information is available at the end of the article Edited by $Y$. Shi
}

to result from multiple factors, including sustained oxidative stress, chronic inflammation, as well as predisposing genetic and environmental factors ${ }^{2,3}$. However, the mechanism of AMD remains unclear.

Retinal pigment epithelium (RPE) cells exist as a monolayer between the neural retina and the choroidal vasculature. An important function of RPE cells is to phagocytose the shedding outer segment discs of the photoreceptors to maintain normal visual function. RPE cells also secrete growth factors, such as fibroblast growth factors, transforming growth factor-beta, insulin-like growth factor-I, ciliary neurotrophic factor, vascular endothelial growth factor, and pigment epithelium-derived factor to maintain retina homeostasis ${ }^{4}$. As the retina ages, RPE cells lose their function. A decrease in RPE-mediated phagocytosis leads to an accumulation of lipofuscin, which 


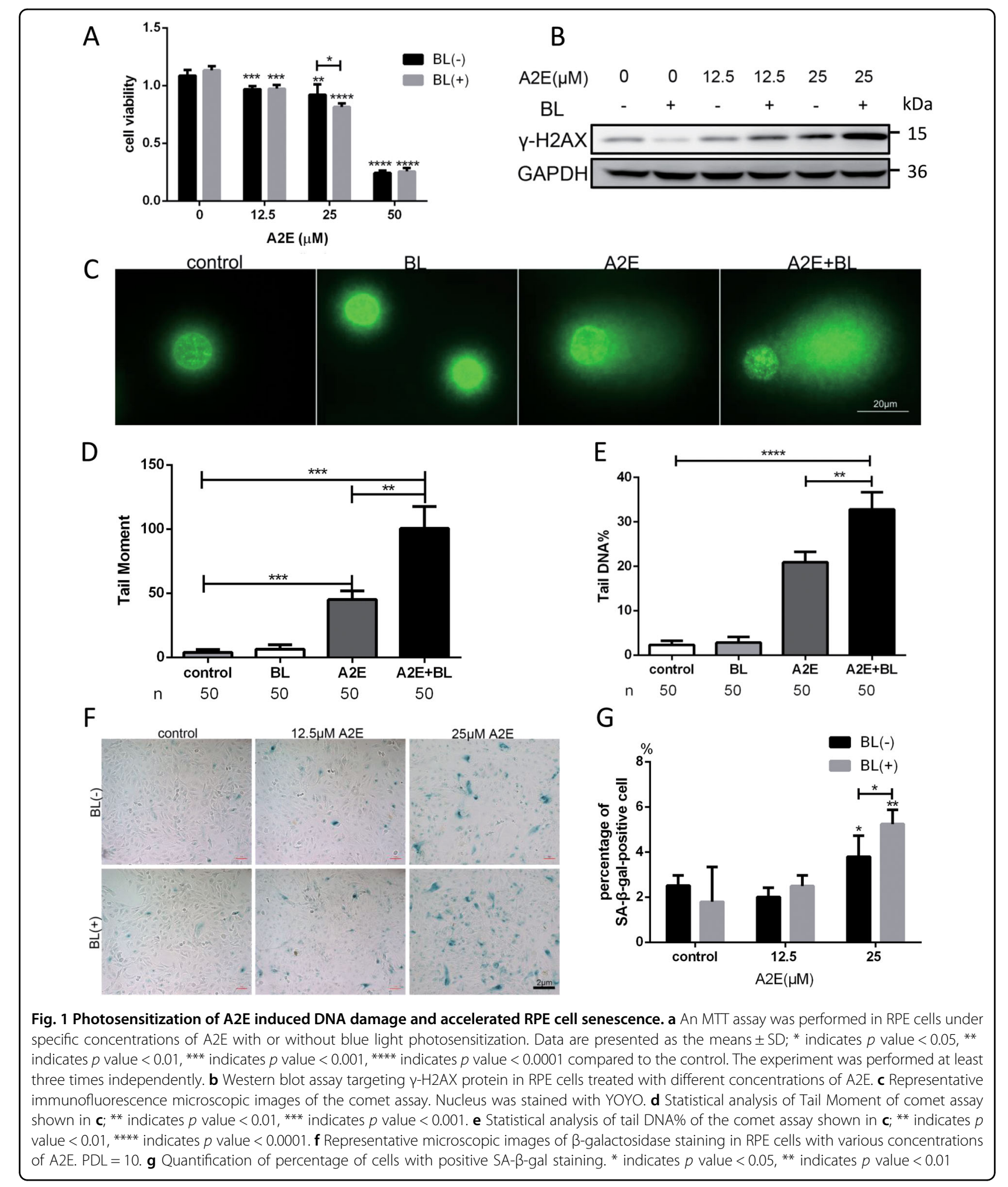

may potentiate RPE cell degeneration and further promote lipofuscin deposition. RPE dysfunction plays an important role in AMD pathogenesis. Maeda et al. showed that a reduction in the number of photoreceptors following intravitreal ornithine-induced degeneration was directly associated with the loss of RPE cells ${ }^{5}$. In geographic atrophy, Kim et al. showed that the decrease in photoreceptors was associated with a loss of RPE cells ${ }^{6}$. 
Age-related lipofuscin accumulation in RPE cells is believed to contribute to AMD pathogenesis? ${ }^{7}$ Nretinylidene- $\mathrm{N}$-retinylethanolamine (named A2E) is a well-characterized fluorophore of RPE lipofuscin, which is generated as a byproduct of the visual cycle ${ }^{8,9}$. Sparrow et al. showed that A2E is the major component of lipofuscin that triggers RPE cell damage ${ }^{10}$. Future studies should explore how A2E mediates RPE cell damage in the field of AMD pathogenesis ${ }^{11}$.

Among the aging hallmarks, gradual telomere loss occurring at each cell division acts as a mitotic clock for cellular senescence ${ }^{12}$. For instance, telomeric DNA shortens with each RPE cell division ${ }^{13,14}$. In vertebrates, telomeric DNA consists of repetitive sequences, such as TTAGGG, which form higher order structures such as tloops and G-quadruplexes ${ }^{15}$. Truncated or dysfunctional telomeres lead to chromosomal damages, transcriptional changes, and cellular senescence ${ }^{16}$. Interestingly, photosensitization of A2E stimulates oxidative DNA damage, such as the formation of 8 -oxo-guanines ${ }^{10,17}$. Since telomeric DNA is rich in guanine residues, telomeres may be a target for A2E-mediated oxidation. Thus, we hypothesized that photosensitization of A2E could accelerate RPE senescence through telomere damage.

\section{Results}

Photosensitization of A2E induces DNA damage and cell senescence in RPE cells

To determine the concentration of A2E that affects the viability of RPE cells, cells were incubated with increasing amounts of A2E for $2 \mathrm{~h}$. Subsequently, the autofluorescence of A2E in RPE cells was measured using an immunofluorescence microscope. The results showed that A2E was phagocytized by RPE cells (Fig. SP1). After $24 \mathrm{~h}$ in fresh medium, cell viability was examined using a cell viability assay. The viability of RPE cells decreased with increasing concentrations of A2E (Fig. 1a). Interestingly, at $25 \mu \mathrm{M}$ A2E, blue light photosensitization further decreased cell viability. Interestingly, this A2E concentration is similar to the amount of A2E present in RPE cells harvested from human donor eyes ${ }^{18}$. Thus, we used A2E at a concentration of $25 \mu \mathrm{M}$ in this study.

We explored whether A2E photosensitization could induce DNA damage based on the level of $\gamma$-H2AX. We observed an increase in the level of $\gamma-\mathrm{H} 2 \mathrm{AX}$ in cells treated with increasing concentrations of A2E based on western blotting, and this increase was exacerbated in the presence of blue light (Fig. 1b).

We performed comet assays under alkaline conditions to examine the formation of DNA double-strand breaks (DSBs). DNA was labeled using YOYO dye (YOYO-1 iodide) (Fig. 1c) and DSBs were analyzed according to the tail DNA and tail moment, which determines the migration of the DNA fragment. In agreement with the level of
$\gamma-\mathrm{H} 2 \mathrm{AX}$ determined by western blotting, treatment with A2E resulted in a sharp increase in DSBs at the single cell level. At $25 \mu \mathrm{M}$ A2E, the DSB level was higher in the presence of blue light (Fig. 1 d,e).

Since DNA damage is associated with cell senescence, we monitored the senescence-associated beta-galactosidase (SA- $\beta$-gal) staining as a marker for cellular senescence. Our results showed that A2E treatment triggered cellular senescence, an effect that was intensified by blue light (Fig. 1f,g). These findings suggest that photosensitization of A2E accelerated the senescence of RPE cells.

\section{Antioxidant NAC treatment alleviates DNA damage and cellular senescence stimulated by $\mathrm{A} 2 \mathrm{E}$ photosensitization}

Since the origin of DNA damage could be due to the oxidative stress caused by A2E photosensitization, we treated cells with the antioxidant $\mathrm{N}$-acetyl cysteine (NAC), which is believed to neutralize free radicals before they can harm cells ${ }^{19}$. As expected, we found that NAC alleviated cell growth arrest (Fig. 2a) and decreased the accumulation of reactive oxygen species (ROS) induced by A2E photosensitization (Fig. 2b), as measured by cell viability assays and fluorescence-activated cell sorting (FACS) analysis of dihydroethidium (DHE) fluorescence intensity. Moreover, NAC rescued, at least in part, the pro-aging effects of A2E photosensitization, i.e., $\gamma$-H2AX increased (Fig. 2c, d) and SA- $\beta$-gal activity (Fig. 2f, g). These results showed that photosensitization of $\mathrm{A} 2 \mathrm{E}$ could induce oxidative stress, resulting in DNA damage and cellular senescence.

\section{Photosensitization of A2E triggers telomere dysfunction}

Telomeres are particularly sensitive to oxidative stress. Thus, we explored whether telomeres could be a target of A2E photosensitization. First, telomere deprotection was evaluated by monitoring co-localization of the shelterin subunit TRF1 (used as a telomere marker) with $\gamma$-H2AX (named TIF for telomere dysfunction-induced foci) (Fig. 2c) ${ }^{20}$. Treatment of RPE cells with A2E increased the number of TIFs per nucleus (Fig. 2e). We examined the telomeres for abnormalities using a telomeric peptide nucleic acid (PNA) probe in metaphase spread staining (Fig. 3a, b). Telomere loss (both single and double strand) was significantly increased upon A2E photosensitization.

Since telomeres were damaged upon A2E photosensitization, we evaluated whether senescence triggered by $\mathrm{A} 2 \mathrm{E}$ is the result of telomere dysfunction. Ectopic expression of the catalytic subunit of telomerase (TERT), which may maintain telomeric DNA, reduced the rate of senescence of RPE cells, as monitored by SA- $\beta$-gal staining (Fig. 3c, d). Interestingly, TERT overexpression decreased the number of senescent cells in the photosensitized A2E treated group (Fig. 3c, d). However, 


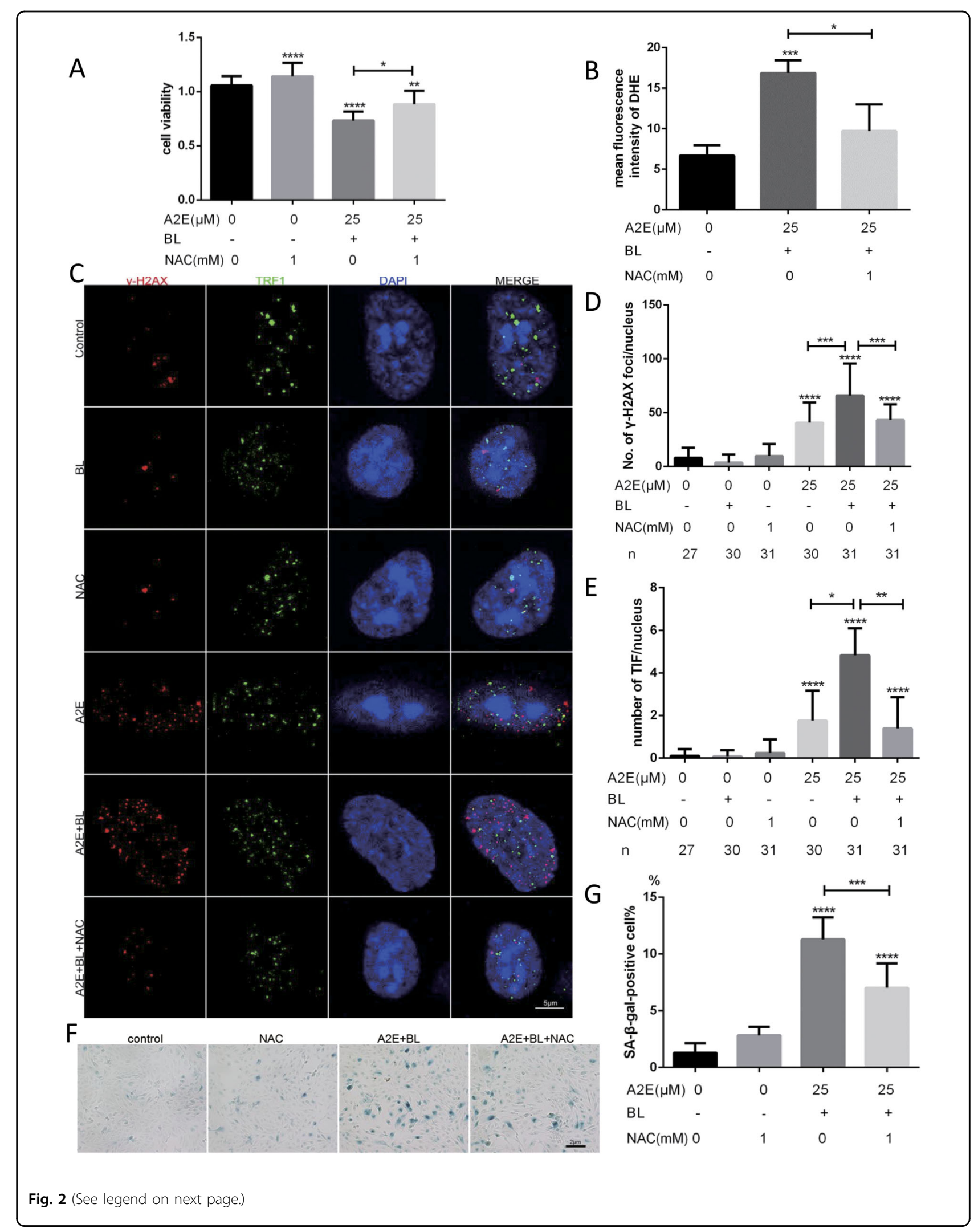


(see figure on previous page)

Fig. 2 NAC alleviates DNA damage (including telomere deprotection) and partially rescues RPE senescence upon A2E photosensitization by decreasing oxidative stress. a An MTT assay was performed in RPE cells treated with $25 \mu \mathrm{M}$ A2E under photosensitization with or without $1 \mathrm{mM}$ NAC. Data are presented as means \pm SD; ${ }^{*}$ indicates $p$ value $<0.05$, ${ }^{* *}$ indicates $p$ value $<0.01$, ${ }^{* * * *}$ indicates $p$ value $<0.0001$. The experiment was performed independently at least three times. $\mathbf{b}$ Statistical analysis of the mean fluorescence intensity of DHE by flow cytometry; ${ }^{*}$ indicates $p<0.05$, *** indicates $p<0.001$ compared to RPE cells treated with $25 \mu \mathrm{M}$ A2E under photosensitization. The experiment was performed independently at least three times. $\mathbf{c}$ Representative images of confocal sections of immunofluorescence assays in RPE cells treated with 1 mM NAC or $25 \mu M$ A2E under photosensitization. $\mathrm{Y}-\mathrm{H} 2 \mathrm{AX}$ foci are labeled red and TRF1 foci are labeled green. $\mathbf{d}$ Quantification of the number of $\mathrm{Y}-\mathrm{H} 2 \mathrm{AX}$ foci per nucleus in RPE cells treated with $1 \mathrm{mM} \mathrm{NAC}$ or $25 \mu \mathrm{M}$ A2E under photosensitization. Data are presented as means \pm SD; ${ }^{* * *}$ indicates $p$ value $<0.001$, ${ }^{* * * *}$ indicates $p<0.0001$. e Quantification of TIFs per nucleus in RPE cells with $1 \mathrm{mM}$ NAC or $25 \mu \mathrm{M}$ A2E under photosensitization. The data are presented as means $\pm \mathrm{SD}$; ${ }^{*}$ indicates $p$ value $<0.05,{ }^{* *}$ indicates $p$ value $<0.01,{ }^{* * *}$ indicates $p<0.0001$. f Representative microscopic images of $\beta$-galactosidase staining in RPE cells treated with $25 \mu \mathrm{M} \mathrm{A2E}$ under photosensitization with or without $1 \mathrm{mM} \mathrm{NAC.} \mathrm{PDL}=15$. g Quantification of the percentage of cells with positive SA- $\beta$-gal staining shown in $\mathbf{e}^{* * *}$ indicates $p<0.001$, ${ }^{* * *}$ indicates $p<0.0001$ compared to control. The experiment was performed independently at least three times

ectopic expression of TRF2 did not rescue senescence triggered by A2E photosensitization (Fig. 3e, f, Fig. SP2). We measured telomere length ( $\mathrm{T} / \mathrm{S}$ ratio) using $\mathrm{RT}-\mathrm{qPCR}$ and found that photosensitization of A2E induced significant telomere erosion, which could be decreased by NAC (Fig. 3g). The rate of senescence in TERTtransduced cells remained elevated upon A2E treatment, suggesting that non-telomeric mechanisms were also involved in A2E photosensitization-mediated senescence.

\section{RPE cell senescence stimulated by photosensitization of A2E triggers the expression of senescence-associated secretory phenotype (SASP) factors}

To investigate the mechanisms involved in A2Emediated senescence, we explored how A2E photosensitization influences gene expression using RNAsequencing (RNA-Seq) and bioinformatics analyses. We considered genes to be differentially expressed if the absolute value of the log2 (fold change) was $>1$ and the $p$ value $<0.05$. We identified 130 genes that were differentially expressed upon photosensitization of A2E, including 45 genes that were upregulated and 85 genes that were downregulated. To understand the functions of the differentially expressed genes (DEGs), we performed Gene Ontology (GO) function annotation. The significantly enriched GO terms included three specific categories (biological process, cellular component, and molecular function). We identified the top six enriched GO terms in the biological process (BP) category (Fig. 4a), and the associated genes are presented in Supplementary Table 1. Interestingly, "inflammatory response", "chronic inflammatory response", and "response to wounding" were significantly enriched among the BP categories (Fig. 4a)

We selected 10 genes with differing expression profiles for further validation. Their mRNA levels, as measured by RT-qPCR, were consistent with those found in the RNASeq analysis (Fig. 4b). The transcript level of IL1 $\beta$, an important pro-inflammatory cytokine, was markedly increased. These findings are in agreement with a previous study suggesting that IL1 $\beta$ may be associated with $\mathrm{AMD}^{21}$. Other inflammatory factors, such as IL13RA2, CXCR4, CXCL8, ICAM-1, IRAK-2, and others, were also significantly increased following A2E photosensitization. Furthermore, we found that other known SASP components, including several matrix metalloproteinases, were downregulated (Fig. 4b, c) ${ }^{21}$. We conclude that A2E photosensitization triggers RPE cell senescence and SASP.

\section{A2E photosensitization-triggered SASP through activation of the NF-KB pathway}

To increase our understanding of the mechanism governing SASP triggered by A2E photosensitization, we tested for enrichment of KEGG pathway terms. KEGG pathway analysis of the upregulated genes showed a significant enrichment $(p<0.05)$ for three KEGG pathway terms, including "NF-kappa B signaling pathway" (Fig. 4d). GO analysis of the upregulated genes also showed a significant enrichment $(p<0.05)$ for $38 \mathrm{GO}$ terms, including "positive regulation of NF-kappa B transcription factor activity" (Fig. 4e). The top $10 \mathrm{GO}$ terms are presented in Fig. 4e. These findings suggest that the NF- $\kappa B$ pathway is activated upon photosensitization of A2E in RPE cells. Thus, we monitored the total endogenous levels of $\operatorname{I\kappa B} \alpha$, which is phosphorylated at Ser32 and subsequently degraded by proteasomes, resulting in the release and nuclear translocation of active NF- $\mathrm{kB}$. Our results showed that the expression of $\mathrm{I} \kappa \mathrm{B} \alpha$ was decreased upon photosensitization of A2E. Next, we measured the expression of phospho-p65 (Ser536) and found that it increased upon photosensitization of A2E. However, the total expression of p65 was not affected (Fig. 5a). We further analyzed the nuclear translocation of active NF- $\mathrm{KB}$ by immunofluorescence (Fig. SP3). Collectively, these results suggest that the NF- $\kappa B$ pathway was activated.

To explore further whether NF- $\mathrm{KB}$ could control SASP stimulated by photosensitization of A2E in RPE cells, we downregulated p65 expression using small interfering 


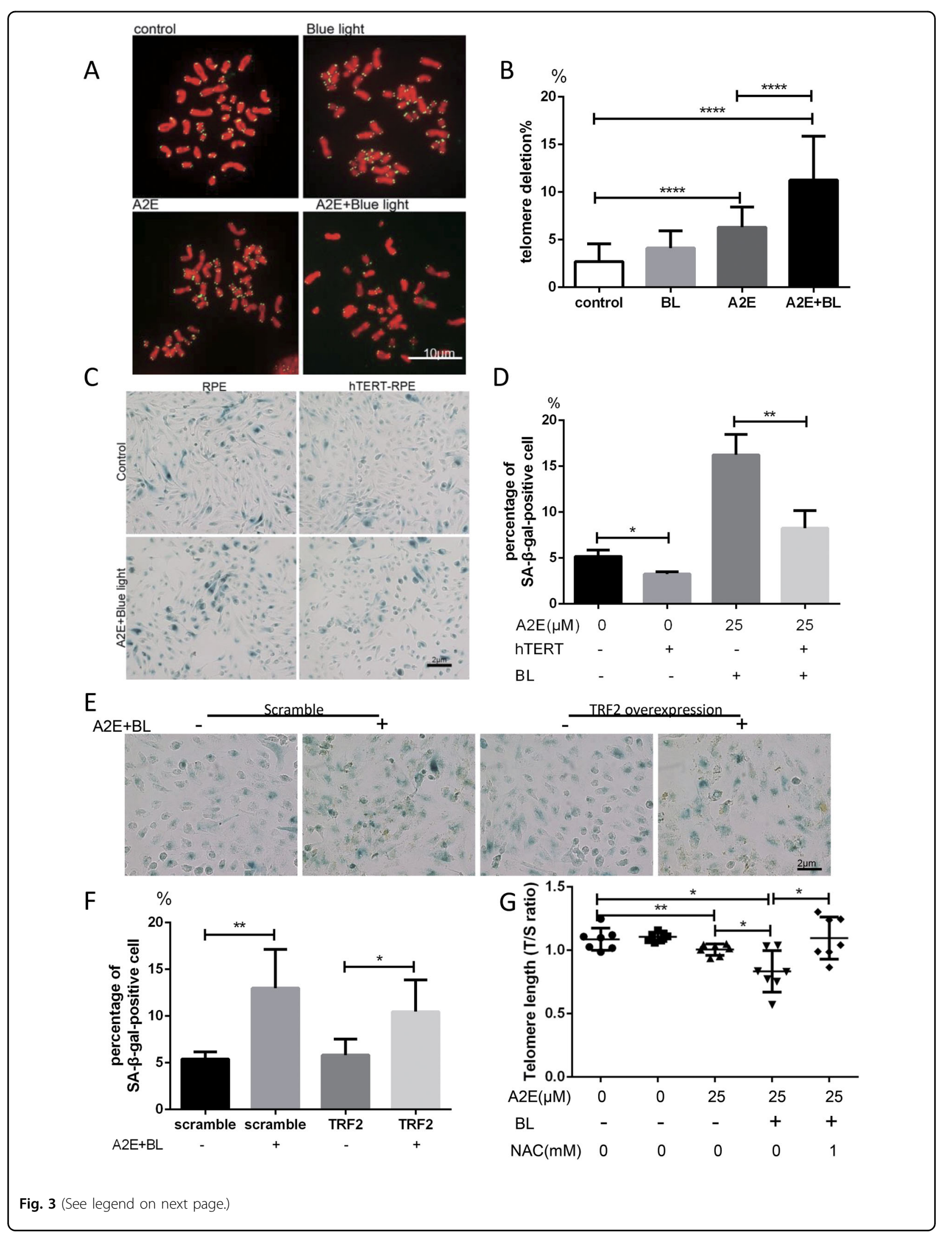


(see figure on previous page)

Fig. 3 Photosensitization of A2E induced telomere deletions, and ectopic expression of hTERT alleviated cellular senescence in RPE cells, whereas TRF2 overexpression had a minimal effect on RPE senescence. a Representative images of telomere FISH in metaphase spreads of RPE cells treated with $25 \mu \mathrm{M}$ A2E under photosensitization. Telo-foci were stained with a PNA probe and DNA was stained with DAPI. b Quantitative analysis of telomere deletion of RPE cells treated with $25 \mu \mathrm{M} \mathrm{A2E}$ under photosensitization. Data are presented as means \pm SD. **** indicates $p<$ 0.0001 . c Representative microscopic images of $\beta$-galactosidase staining in RPE and hTERT-RPE cells treated with $25 \mu \mathrm{M}$ A2E under photosensitization. $\mathrm{PDL}=32$. d Quantification of the percentage of cells with positive SA- $\beta$-gal staining shown in $\mathbf{c}_{;}{ }^{*}$ indicates $p$ value $<0.05$, ${ }^{* *}$ indicates $p$ value $<0.01$. The experiment was performed independently at least three times. e Representative microscopic images of $\beta$-galactosidase staining in RPE and TRF2 overexpression-RPE cells treated with $25 \mu \mathrm{M}$ A2E under photosensitization. $\mathbf{f}$ Quantification of the percentage of cells with positive SA- $\beta$-gal staining shown in $\mathbf{c}_{;}{ }^{*}$ indicates $p$ value $<0.05,{ }^{* *}$ indicates $p$ value $<0.01$. The experiment was performed independently at least three times. $\mathbf{g}$ Telomere length (T/S ratio) measured by RT-qPCR; * indicates $p$ value $<0.05,{ }^{* *}$ indicates $p$ value $<0.01$ compared to control

RNA (siRNA) in RPE cells (Fig. 5b). We found that knockdown of p65 protein efficiently decreased the expression of key SASP factors, including IL8, IL6, IL17A, and ICAM1 (Fig. 5c). These results are in agreement with previous studies in other models, which showed that NF$\kappa \mathrm{B}$ acts as a master regulator of the $\mathrm{SASP}^{22}$.

Recent studies suggest that SASP can reinforce senescence arrest and mediate paracrine effects, triggering senescence in neighboring cells ${ }^{23}$. To explore whether the SASP of A2E-treated RPE cells show this paracrine effect, we used a Transwell system to co-culture A2E-treated senescent cells with untreated A2E cells. After $24 \mathrm{~h}$ of coculture with A2E-treated senescent cells, untreated RPE cells present in the neighboring chamber became senescent based on SA- $\beta$-gal activity (Fig. 5 d, e). Moreover, the knockdown of p65 in senescent cells caused by A2E photosensitization decreased the rate of senescence induced in the neighboring chamber (Fig. 5d, e). Collectively, these results indicate that paracrine factors produced by senescent A2E-treated RPE cells induced senescence in neighboring cells.

\section{Discussion}

Epidemiological surveys have shown that advanced age is the main risk factor for $\mathrm{AMD}^{24,25}$. Aging has been defined as "the progressive accumulation of changes with time that are associated with or responsible for the everincreasing susceptibility to disease and death which accompanies advancing age" ${ }^{26}$. Cellular senescence can be defined as a permanent arrest of the cell cycle coupled to phenotypic changes, including DNA damage response activation, SA- $\beta$-gal overexpression, and the secretion of growth factors, tissue-remodeling enzymes, and various pro-inflammatory molecules forming the $\mathrm{SASP}^{27}$. The accumulation of senescent cells in tissues contributes to normal and pathological aging 28 .

Several reports suggest that increased DNA damage and downregulation of DNA repair capacities in RPE cells play a role in the pathogenesis of retina degeneration pathol$\mathrm{ogy}^{29-32}$. We confirmed these results by monitoring the level of DNA damage response protein $\gamma \mathrm{H} 2 \mathrm{AX}$ in A2E- laden RPE cells. Interestingly, we showed that telomeres are targeted by A2E photosensitization, as revealed by an increased recruitment of DNA damage response factor at telomeres and an increased proportion of telomere loss. In agreement with a causal role of telomere damage with the outcome of A2E-treated RPE cells, the accelerated RPE cellular senescence triggered by A2E photosensitization is rescued by ectopic expression of TERT, indicating that telomere DNA loss plays an important role in photosensitization of A2E-induced RPE cell senescence. The fact that TRF2 overexpression does not rescue the A2E-induced senescence suggests that the telomere alteration triggering senescence does not result from TRF2 dysfunction.

Oxidative stress is believed to play a role in the development of AMD due to the high oxidative stress environment of the fundus ${ }^{2}$. Moreover, telomere length decreases with oxidative stress $^{33}$. Indeed, we found that the antioxidant NAC could partially protect against cellular senescence, as well as the DNA damage caused by photosensitization of A2E in RPE cells. This suggested that A2E-induced cell senescence was a complicated process that partially depends on telomere dysfunction.

Recent studies suggest that senescent cells create a microenvironment through SASP to mediate cross-talk among neighboring cells in a paracrine manner ${ }^{34}$. It has now been shown that SASP components take part in the senescence process. Secreted factors from senescent cells may trigger and/or accelerate senescence process or, otherwise stimulate proliferation and/or transformation of adjacent immortalized cells ${ }^{35}$. IL6, IL8, and other cytokines which attract immune cells play an important role in immune surveilance and subsequent elimination of senescent cells. ${ }^{36}$. According to the above biological process, SASP can facilitate tumor regression or the resolution of wound healing responses ${ }^{36,37}$. Despite the potential importance of SASP in senescence, how the process is regulated in RPE cells remains unclear, and its impact on age-related retina degeneration disease has not been directly assessed. 


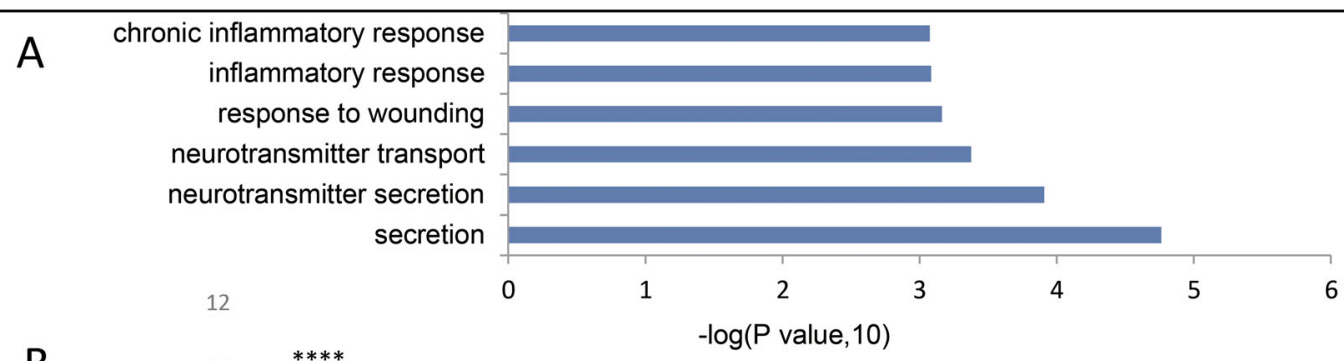

B

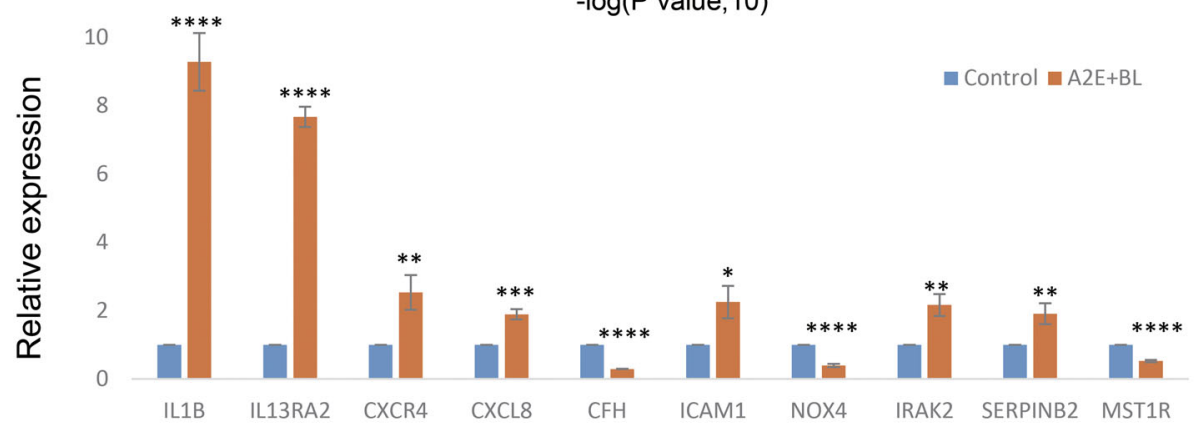

C

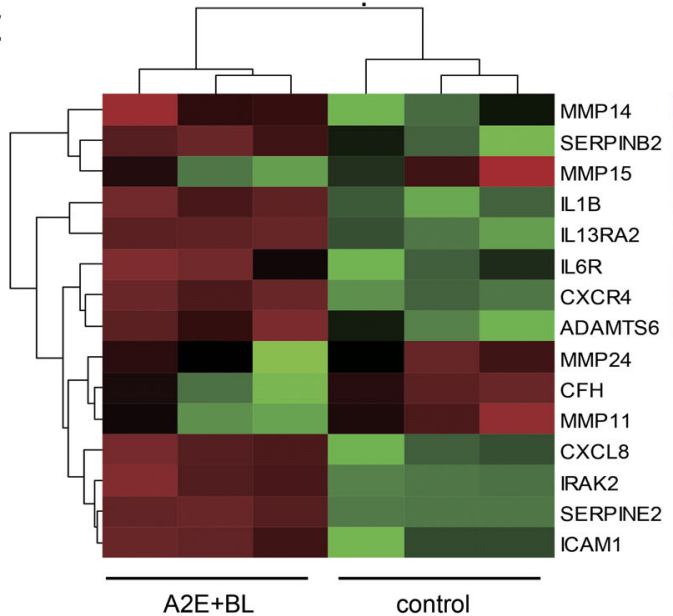

$\mathrm{D}$

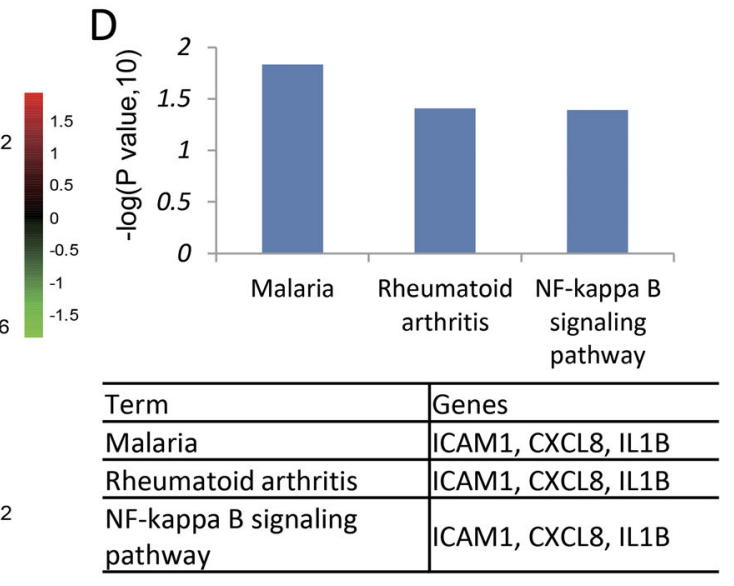

$\mathrm{E}$

regulation of MAP kinase activity positive regulation of NF-kappaB transcription..

regulation of cell death regulation of programmed cell death regulation of DNA binding

regulation of apoptosis

regulation of transcription factor activity positive regulation of binding

positive regulation of DNA binding positive regulation of transcription factor activity

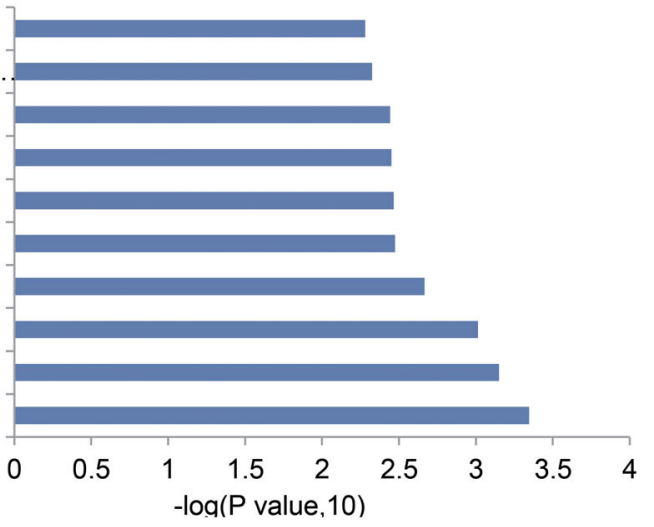

Fig. 4 GO analysis and classification of differentially expressed genes. a Gene Ontology analysis and classification of differentially expressed genes from control and RPE cells treated with $25 \mu \mathrm{M} \mathrm{A2E}$ under photosensitization into biological processes (top six). $\mathbf{b}$ Validation of the expression of the pro-inflammatory genes by RT-qPCR; ${ }^{* *}$ indicates $p$ value $<0.01,{ }^{* * *}$ indicates $p$ value $<0.001,{ }^{* * * *}$ indicates $p$ value $<0.0001$. The experiment was performed independently at least three times. $\mathbf{c}$ Heat map of genes related to SASP. $\mathbf{d}$ KEGG pathway analysis of significantly upregulated genes with $25 \mu \mathrm{M}$ A2E under photosensitization. e Gene Ontology analysis and classification of significantly upregulated genes under $25 \mu \mathrm{M}$ A2E with photosensitization into biological processes (top 10) 


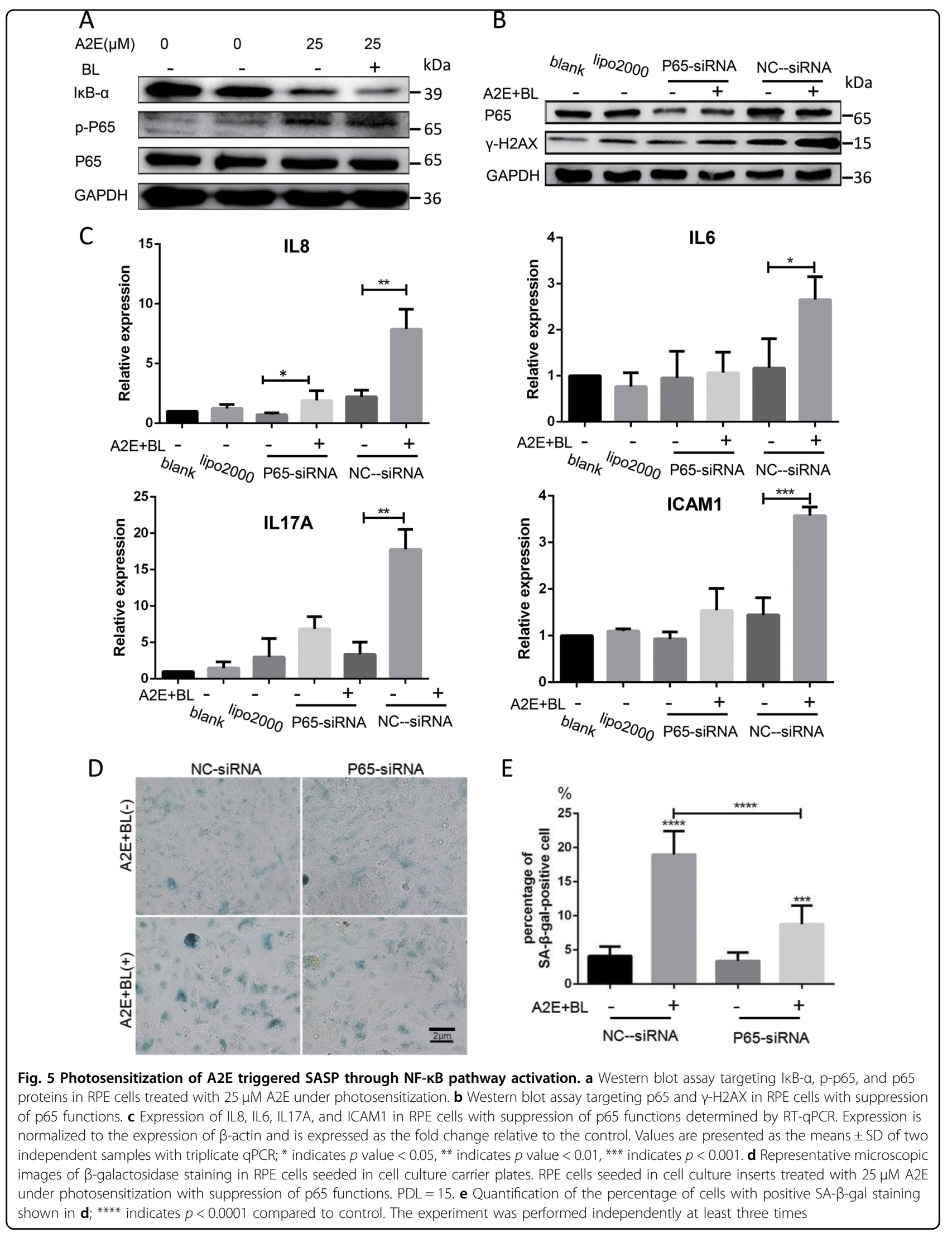


In this report, we show that photosensitization of A2E changed the gene expression profile in RPE cells based on RNA-Seq analysis. Our results show that the expression of SASP genes was significantly increased. In addition, the pro-inflammatory cytokines IL $1 \beta$ and CXCL8 are associated with AMD pathogenesis ${ }^{38}$. By implicating NF- $\mathrm{kB}$ as a major transcriptional modulator in senescence that is required for SASP, our study further supports the importance of SASP in senescence. Indeed, by disrupting p65 (the key mediator of this program), we showed that SASP factors were significantly decreased and that photosensitization of A2E-induced senescence could be rescued. Thus, photosensitization of A2E triggers SASP in RPE cells, which can lead to senescence in neighboring cells. Consequently, our study increases our understanding on the mechanism by which A2E induces RPE cell senescence and the action of NF- $\mathrm{KB}$ in age-related retina degeneration disease.

In conclusion, our study demonstrates that photosensitization of A2E induces DNA damage, including telomere deprotection, further accelerating RPE cell senescence. In addition, we show that A2E photosensitization-induced RPE senescence triggers SASP $^{39}$. The inflammatory environment created by this SASP may trigger and accelerate age-related retina degeneration pathology, similar to AMD. This hypothesis is in agreement with a previous report showing that A2E induced inflammatory chemokine and cytokine production $^{40,41}$. Our results suggest that A2E photosensitization leads to a paracrine effect, affecting the entire retina environment, which may consequently drive retina degeneration pathology (Fig. 6). In addition, our results show that telomere dysfunction is an important cause of A2E photosensitization-induced RPE senescence, suggesting that telomere-protecting molecules may protect against cell senescence ${ }^{42}$.

\section{Materials and methods}

\section{Cell culture, transfections, and lentivirus production and} infection

Human adult RPE cells (APRE-19; American Type Culture Collection, Manassas, VA, USA) were cultured in Dulbecco's modified Eagle's/Ham's F12 (Invitrogen, Grand Island, NY, USA) with $10 \%$ fetal bovine serum (Invitrogen), $100 \mu \mathrm{g} / \mathrm{mL}$ streptomycin, and $100 \mathrm{U} / \mathrm{mL}$ penicillin at $37^{\circ} \mathrm{C}$ under $5 \% \mathrm{CO}_{2}$ and $95 \%$ humidified air. Transfection of plasmid DNA was performed with lipofectamine 2000 reagent (Invitrogen), as described previously. Empty vector or vector expressing TERT or TRF2 were produced by transient transfection of Human Embryonic Kidney 293 Phoenix cell lines with two other packaging plasmids, p8.91 and pVSVg. Next, 48 and $72 \mathrm{~h}$ post-transfection, the infectious supernatant was collected and applied to the target cells. The stable

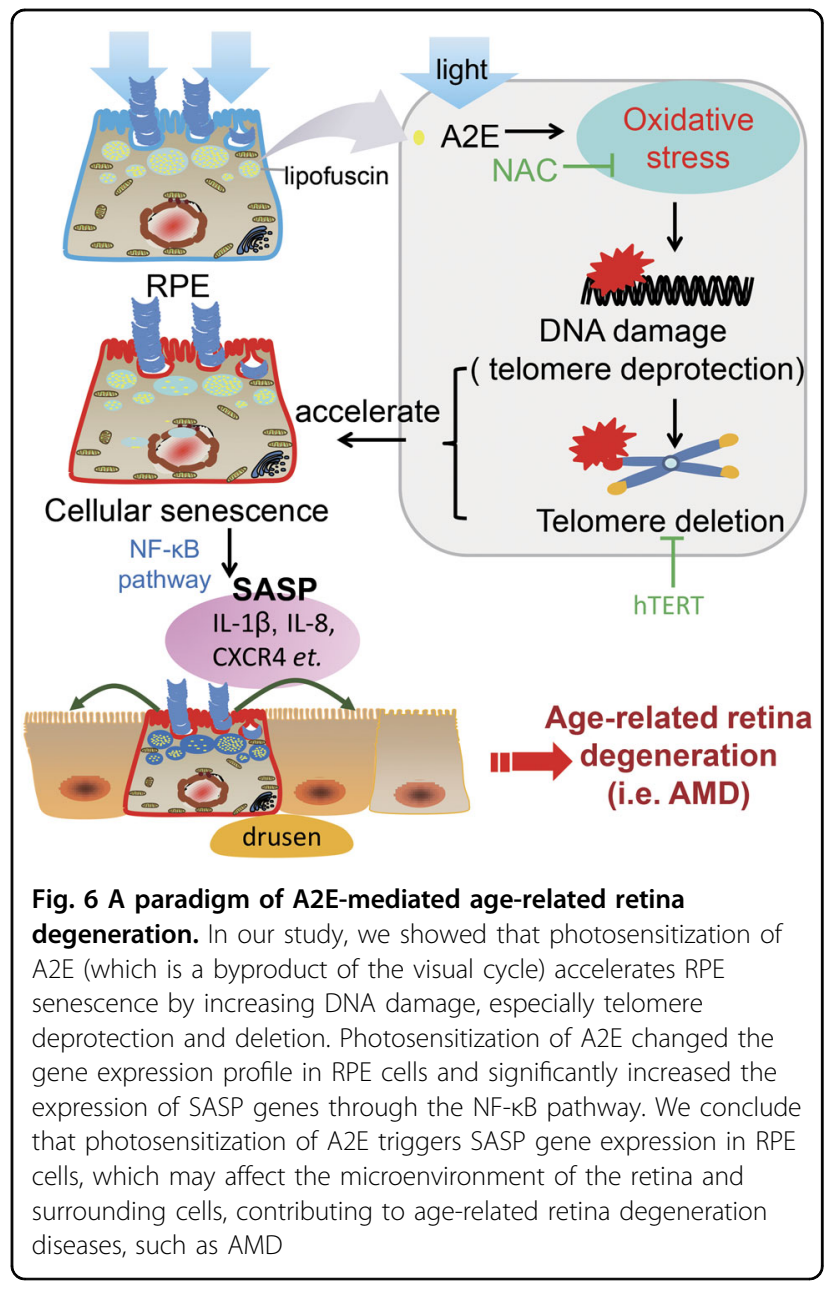

hTERT-RPE cell line was selected with $1 \mu \mathrm{g} / \mathrm{mL}$ puromycin for 1 month. The Transwell assay was performed using a NUNC chamber (Cat. No.140640; NUNC, Rochester, NY, USA).

\section{RNA interference}

RPE cells were transfected with double-stranded siRNA or negative control siRNA using Lipofectamine ${ }^{\mathrm{TM}} 2000$ Transfection Reagent (Cat. No. 116680; Invitrogen, USA). Target sequences were as follows: 5'-GCCCUAUCCCUUUACGUCA-3' for p65. Double-strand siRNAs were synthesized by Shanghai GenePharma (China).

\section{A2E formation and treatment}

A2E was synthesized from all-trans-retinal (Sigma Aldrich, St. Louis, MO, USA) and ethanolamine at a 2:1 molar ratio, as described previously ${ }^{43}$. A2E was dissolved in dimethyl sulfoxide at a concentration of $25 \mathrm{mM}$ and stored at $-80^{\circ} \mathrm{C}$ in the dark as a stock solution, as described previously ${ }^{44}$.

RPE cells were incubated with A2E in culture medium for $2 \mathrm{~h}$. Cells were then washed three times to remove 
extracellular A2E. After A2E loading, RPE cells were exposed to $460 \pm 20 \mathrm{~nm}$ wavelength light (4000lx; Osram, Augsburg, Germany) for $20 \mathrm{~min}$, as described previously $^{40}$.

\section{Cell viability assay}

The Cell Titer 96 Aqueous One Solution cell proliferation assay (Promega, Madison, WI, USA) was performed as described previously ${ }^{44}$. RPE cells were seeded in 96-well flat-bottomed microliter plates in eight repeat cultures at a concentration of $1 \times 10^{4}$ cells/well. After treatment, each well was incubated with $20 \mu \mathrm{M}$ MTS assay solution for $2 \mathrm{~h}$ at $37^{\circ} \mathrm{C}$ and the absorbance was measured using an enzyme-linked immunosorbent assay plate reader at $490 \mathrm{~nm}$ emission wavelength. Cell viability was expressed as the percentage of absorbance in cells with indicated treatments to that in cells with solvent control treatment.

\section{Telomere length assessment by quantitative real-time PCR}

Telomere length was measured in genomic DNA extracted from RPE cells by quantitative real-time PCR, as described by Cawthon ${ }^{45}$. The primer sequences were: tel 1, 5'-GGTTTTTGAGGGTGAGGGTGAGGGTGAGGG T-3'; tel 2, 5'-TCCCGACTATCCCTATCCCTATCCC TATCCCTATCCCTA-3'; 36B4u, 5'-CAGCAAGTGGG AAGGTGTAATCC-3'; 36B4d, 5'-CCCATTCTATCATC AACGGTACAA-3'. The RT-PCR reaction volume was as follows: for telomere amplification tell, $30 \mathrm{ng}$ of genomic DNA in $\mathrm{H}_{2} \mathrm{O}$ was added to $10 \mu \mathrm{L}$ of $2 \times$ SYBR Green buffer, $675 \mathrm{nmol} / \mathrm{L}$ Tel-1 primer, $1350 \mathrm{nmol} / \mathrm{L}$ Tel-2 primer, and $\mathrm{H}_{2} \mathrm{O}$ to a final volume of $20 \mu \mathrm{L}$; and for the amplification of the single copy gene 36B4: $30 \mathrm{ng}$ of genomic DNA in $\mathrm{H}_{2} \mathrm{O}$ was added to $10 \mu \mathrm{L}$ of $2 \times$ SYBR Green buffer, $800 \mathrm{nmol} / \mathrm{L}$ of $36 \mathrm{~B} 4 \mathrm{u}$ primer, $800 \mathrm{nmol} / \mathrm{L} 36 \mathrm{~B} 4 \mathrm{~d}$, and $\mathrm{H}_{2} \mathrm{O}$ to a final volume of $20 \mu \mathrm{L}$. The T/S ratio was calculated as follows: $\left[2^{\mathrm{CT} \text { (telomeres) }}\right.$ / $\left.2^{\mathrm{CT}(\text { single copy gene) }}\right]=2^{-\Delta \mathrm{CT}}$. Differences were calculated using Student's $t$-test at a significance level of 0.05 in Graphpad Prism 6.0 software. All expression analysis was performed for three biological repeats.

\section{Western blot}

Cells were lysed in lysis buffer and boiled for $15 \mathrm{~min}$. Proteins were separated by SDS-polyacrylamide gel electrophoresis, transferred to polyvinylidene difluoride membrane, and probed with antibodies specific for $\gamma$-H2AX (1:1000 dilution, \#2577, CST), for IкB $\alpha$ (1:1000 dilution, \#9242, CST), for Phospho-NF-кB p65 (Ser536) (1:1000 dilution, \#3033), p65 (1:1000 dilution, \#8242, CST). GAPDH (1:5000, dilution, 60004-1-Ig, Proteintech) antibodies were used to determine the protein amounts as a loading control.

\section{Immunofluorescence}

Slides were either fixed with $\mathrm{MeOH}$ at $-20^{\circ} \mathrm{C}$ or with $4 \%$ formaldehyde at room temperature (RT) for 10 to 15 $\mathrm{min}$, and were then incubated with blocking buffer $(0.8 \times$ PBS, $50 \mathrm{mM} \mathrm{NaCl}, 0.5 \%$ Triton X 100, 3\% milk) for $1 \mathrm{~h}$, followed overnight by incubation at $4{ }^{\circ} \mathrm{C}$ with primary antibody to TRF2 (ab217529, 1/100, abcam), to p65 (\#8242, 1/200, CST), to $\gamma$-H2AX (ab2893, 1/100, abcam) and mouse polyclonal antibody to TRF1 (ab10579, 1/100, abcam) in $0.8 \times$ PBS, $50 \mathrm{mM} \mathrm{NaCl}, 0.5 \%$ Triton X 100 , and $3 \%$ milk. Cells were then washed three times for 10 min in $0.8 \times$ PBS, $50 \mathrm{mM} \mathrm{NaCl}$, and $1.5 \%$ skimmed milk at RT. Incubation with donkey polyclonal anti-mouse ALEXA488 (A21202; Molecular Probes) and donkey polyclonal anti-rabbit ALEXA555 (A31752; Molecular Probes) antibodies was performed for $1 \mathrm{~h}$ at $37^{\circ} \mathrm{C}$ in the dark in $0.8 \times \mathrm{PBS}, 50 \mathrm{mM} \mathrm{NaCl}, 0.5 \%$ Triton X 100, and $3 \%$ skimmed milk. All antibody incubations were performed in a moist chamber. Cells were then washed three times for $10 \mathrm{~min}$ in $0.8 \times \mathrm{PBS}, 50 \mathrm{mM} \mathrm{NaCl}$, and $0.5 \%$ Triton X 100. Slides were then rinsed in PBS, counterstained with 4',6-diamidino-2-phenylindole (DAPI), mounted in VECTASHIELD, and stored at $4{ }^{\circ} \mathrm{C}$ in the dark.

\section{SA- $\beta$-gal staining}

The SA- $\beta$-gal staining assay was performed using an SA- $\beta$-gal staining kit (Beyotime, China) and performed as per the manufacturer's instructions.

\section{Comet assay}

For each condition, 7000 cells were pelleted and resuspended in $50 \mu \mathrm{L}$ of $0.5 \%$ low melting point agarose dissolved in $1 \times \mathrm{PBS}$ at $42^{\circ} \mathrm{C}$. The suspension was immediately laid onto a comet slide (4250-200-03, Trevigen). Agarose was allowed to solidify at $4{ }^{\circ} \mathrm{C}$ for $20 \mathrm{~min}$. The comet slides were then immersed in prechilled lysis solution $(2.5 \mathrm{NaCl}, 100 \mathrm{mM}$ EDTA, $10 \mathrm{mM})$ at $4{ }^{\circ} \mathrm{C}$ for 90 $\mathrm{min}$ in the dark. After this treatment, comet slides were placed in a horizontal electrophoresis unit and allowed to equilibrate in electrophoresis buffer for $5 \mathrm{~min}$ at $4{ }^{\circ} \mathrm{C}$ in the dark. Migration was then performed in $0.5 \times \mathrm{TBE}$ buffer $(\mathrm{pH}=8)$ at $40 \mathrm{~V}$ for $20 \mathrm{~min}$. Slides were then placed in ethanol (100\%) for $30 \mathrm{~min}$ at $4{ }^{\circ} \mathrm{C}$ (slides can be stored for few days under these conditions). Slides were then thoroughly air-dried and the DNA was stained with YOYO-1 for $10 \mathrm{~min}$.

Comet analysis was performed using the Tritek Comet Score freeware, which measures a wide range of densitometric parameters for each comet. The tail moment (= tail length $\times$ DNA in the tail / total DNA) was recorded for each comet (40-50 cells). Student's $t$-test was used to generate statistics. 


\section{Chromosome PNA-FISH}

PNA-FISH was performed as described previously ${ }^{46}$. Briefly, cells were washed with PBS and $10 \mathrm{~mL}$ of fresh culture medium with $60 \mu \mathrm{L}$ of colcemid $(10 \mathrm{ng} / \mathrm{mL})$ added and incubated for $1 \mathrm{~h}$ at $37^{\circ} \mathrm{C}$, after which the cells were collected. Cells were then transferred to a labeled $50-\mathrm{mL}$ tube and centrifuged at $300 \times g$ for $10 \mathrm{~min}$ at $4{ }^{\circ} \mathrm{C}$. The supernatant was then aspirated, leaving $1 \mathrm{~mL}$ in the tube, and the pellet was suspended by pipetting. A total of $5 \mathrm{~mL}$ of prewarmed $\mathrm{KCl}\left(37^{\circ} \mathrm{C}\right)$ was added in a dropwise fashion. Next, $25 \mathrm{~mL}$ of $\mathrm{KCl}$ was added and mixed by inverting. A total of $100 \mu \mathrm{L}$ of fresh fixative (methanol/ acetic acid $=3 / 1$ ) was added and mixed. Next, we incubated the tubes at $37^{\circ} \mathrm{C}$ for $15 \mathrm{~min}$ and centrifuged at $300 \times g$ for $10 \mathrm{~min}$ at $4{ }^{\circ} \mathrm{C}$. The supernatant was then aspirated, leaving $1 \mathrm{~mL}$ in the tube, and the pellet was resuspended. We then added $5 \mathrm{~mL}$ of fresh fixative in a dropwise fashion and then added an additional $25 \mathrm{~mL}$ of fixative and incubated overnight at $4{ }^{\circ} \mathrm{C}$. We next centrifuged the fixed cells at $300 \times g$ for $10 \mathrm{~min}$ at $4{ }^{\circ} \mathrm{C}$ and aspirated the fixative, leaving $2 \mathrm{~mL}$ in the tube. Next, precooled slides were placed in the humidity chamber and the resuspended cells were added to a slide. We then allowed the slides to dry overnight.

Next, slides were fixed in $4 \%$ formaldehyde for $2 \mathrm{~min}$, followed by washing three times. We then prewarmed 50 $\mathrm{mL}$ of $0.01 \mathrm{M} \mathrm{HCl}$ to $37^{\circ} \mathrm{C}$ and added $50 \mu \mathrm{L} / 10 \mathrm{~mL}$ of pepsin stock $(100 \mu \mathrm{g} / \mu \mathrm{L}$, Sigma) to it. Slides were then put in the solution and incubated for $10 \mathrm{~min}$ at $37^{\circ} \mathrm{C}$, after which the slides were fixed in $4 \%$ formaldehyde for $2 \mathrm{~min}$ following washing three times for $10 \mathrm{~min}$ each. Next, slides were dehydrated by $50 \%, 75 \%$, and $100 \%$ ethanol. Once dry, we applied $120 \mu \mathrm{L}$ of PNA probe in blocking buffer (70\% deionized formamide, $100 \mathrm{mM}$ Tris, $\mathrm{pH} 7.2$, $1 \%$ blocking reagent) to a $24 \times 60 \mathrm{~mm}$ coverslip and touched the slide to the coverslip. The slide was denatured at $80^{\circ} \mathrm{C}$ for $3 \mathrm{~min}$, after which the slides were incubated for $2 \mathrm{~h}$ at $37^{\circ} \mathrm{C}$. Then, the slide washed twice in washing buffer I (70\% deionized formamide, $10 \mathrm{mM}$ Tris, $\mathrm{pH} 7.2)$ for $15 \mathrm{~min}$ each time. Slides were washed in washing buffer II $(0.05 \%$ Tween-20, $50 \mathrm{mM}$ Tris, pH 7.4, $150 \mathrm{mM} \mathrm{NaCl}$ ) three times for $5 \mathrm{~min}$ each. We then stained the slides for $3 \mathrm{~min}$ in DAPI and washed the slides for $5 \mathrm{~min}$ in PBS. Next, VECTASHIELD was applied and covered with coverslips, after which the slides were stored at $4{ }^{\circ} \mathrm{C}$.

\section{Microscopy}

PNA-FISH and comet-FISH assays were recorded on an AxioPlan microscope from ZEISS, equipped with a PlanApochrom at $63 \times$, NA 1.4, oil immersion lens, and a cooled CCD camera (CoolSNAP HQ, Photometrics). Image acquisition, processing, and analysis software were from MetaMorph (Molecular Devices). Images of immunofluorescence were recorded using a confocal microscope from Leica.

\section{ROS labeling and FACS analysis}

ROS was labeled using DHE (Invitrogen, Eugene, OR, USA). Cells were incubated with $2.5 \mu \mathrm{M}$ DHE in the dark at $37^{\circ} \mathrm{C}$ for $30 \mathrm{~min}$ and then washed three times with PBS and detected by flow cytometry, as reported previously ${ }^{44}$.

\section{RNA analyses}

Total RNA samples were isolated using TRlzol (\#15596018, Invitrogen) and then reverse transcribed into cDNAs using a kit from Takara (\#RR047A).

\section{RNA-Seq and bioinformatics analyses}

RNA-Seq was performed according to the manufacturer's guidelines and previous protocols (C-10365, Life Technologies ${ }^{47}$ ). RNA deep-sequencing analyses were performed at Epigenetics Key Laboratory of Institutes of Biomedical Sciences (IBS) of Fudan University (Shanghai, China). For bioinformatics analyses, the sequence reads were mapped to human hg19 reference genome transcripts and genome databases using TopHat software allowing 2-bp mismatches per 125-bp seed. Transcript structure and abundance were estimated using Cufflinks software, and differential expression analysis was performed using Cuffdiff software ${ }^{48}$. The cutoff value of differential expression gene was: $\mid \log 2$ (fold change) $\mid>1$, $p$-value $<0.05$. GO enrichment analysis was performed using DAVID ver. 6.7 (Database for Annotation, Visualization and Integrated Discovery), which is a web-based application (https://david.ncifcrf.gov/)

\section{Real-time PCR (RT-PCR) validation}

RT-PCR primer sequences were designed using Primer3 web software (version 4.0.0). The primer sequences used are provided in Supplementary Table S2. The GAPDH gene was used to calculate the relative fold differences based on comparative cycle threshold $\left(2^{-\Delta \Delta C t}\right)$ values. The RT-PCR procedure was as follows: $1 \mu \mathrm{L}$ of cDNA in $\mathrm{H}_{2} \mathrm{O}$ was added to $5 \mu \mathrm{L}$ of $2 \times$ SYBR Green buffer, $0.1 \mu \mathrm{M}$ each primer, and $\mathrm{H}_{2} \mathrm{O}$ to a final volume of $10 \mu \mathrm{L}$. Differences between the two samples were calculated using Student's $t$-test at a significance level of 0.05 in Graphpad Prism 6.0 software. All expression analysis was performed for three biological repeats and the average values of three repeats values were shown in the figures.

\section{Statistical analysis}

Based on the univariate test, continuous normal variables were expressed as the mean value \pm SD. Parametric variables of normal distribution were analyzed either by the two-tailed $t$-test or the $F$-test of ANOVA, followed by the Duncan test for each two group comparison. Results 


\section{were considered significant at $p<0.05$. Statistical analysis was performed with Graphpad Prism 6.0 software.}

\section{Acknowledgements}

This study was supported by the National Natural Science Foundation of China (grant numbers 81730026, 81425006, and 81470640), the Foundation of Shanghai Jiaotong University School of Medicine for Translational Medicine Innovation project (grant number 15ZH4005), the Foundation of Shanghai Engineering Technology Research Center for Construction project (grant number 16dz2251500), the Foundation of the Shanghai Science and Technology Committee (grant number 16140900800). Work in the JY/YL laboratories was supported by the National Natural Science Foundation of China (grant numbers 81171846, 81270433, $81372099,81471400,81522017$, and 81671900), the Shanghai Foundation for Basic Research of Science and Technology, China (grant number 13JC1404001), the Foundation of the Shanghai Science and Technology Committee (grant number 11ZR1422100), and Shanghai Municipal Education Commission --Gaofeng Clinical Medicine Grant (Grant number 20161408).

Funding institutions had no role in the study design, data collection and analysis, the decision to publish, or preparation of the manuscript. Thanks to Wenjing Li, Wenqi Li, and Hongjie Shen from Epigenetics Key Laboratory of Institutes of Biomedical Sciences (IBS) of Fudan University for their help with RNA-Seq analysis. Thanks to Qing Xie and Zi Wang for their valuable suggestions for preparation of the manuscript. Thanks to Lianxiang Chen for the help for comet assay and immunostaining analysis.

\section{Author details}

'Department of Ophthalmology, Shanghai General Hospital (Shanghai First People's Hospital), Shanghai Jiao Tong University School of Medicine, No. 100 HaiNing Road, 200080 Shanghai, PR China. ${ }^{2}$ International Laboratory in Hematology and Cancer (LIA), Shanghai Jiao Tong University School of Medicine/Ruijin Hospital/CNRS/INSERM/Nice University, Pôle Sino-Français de Recherche en Sciences du Vivant et Génomique, Shanghai Ruijin Hospital, Affiliated to Shanghai Jiaotong University, 200025 Shanghai, PR China. ${ }^{3}$ Shanghai Engineering Center For Visual Science And Photomedicine, Shanghai, China. ${ }^{4}$ Shanghai Key Laboratory of Ocular Fundus Diseases, Shanghai, China. ${ }^{5}$ School of Biology and Agriculture, Shanghai Jiao Tong University, Shanghai, China

\section{Conflict of interest}

The authors declare that they have no conflict of interest.

\section{Publisher's note}

Springer Nature remains neutral with regard to jurisdictional claims in published maps and institutional affiliations.

Supplementary Information accompanies this paper at (https://doi.org/ 10.1038/s41419-017-0200-7).

Received: 28 July 2017 Revised: 6 November 2017 Accepted: 28 November 2017

Published online: 07 February 2018

\section{References}

1. Clemons, T. E., Milton, R. C., Klein, R., Seddon, J. M. \& Ferris, F. R. Risk factors for the incidence of Advanced Age-Related Macular Degeneration in the AgeRelated Eye Disease Study (AREDS) AREDS report no. 19. Ophthalmology 112 533-539 (2005)

2. Beatty, S., Koh, H., Phil, M., Henson, D. \& Boulton, M. The role of oxidative stress in the pathogenesis of age-related macular degeneration. Sur. Ophthalmol. 45, 115-134 (2000).

3. Khandhadia, S. \& Lotery, A. Oxidation and age-related macular degeneration: insights from molecular biology. Expert Rev. Mol. Med. 12, e34 (2010).

4. Bhutto, I. \& Lutty, G. Understanding age-related macular degeneration (AMD): relationships between the photoreceptor/retinal pigment epithelium/Bruch's membrane/choriocapillaris complex. Mol. Aspects Med. 33, 295-317 (2012).

5. Maeda, $\mathrm{H}$. et al. Apoptosis of photoreceptor cells in ornithine-induced retinopathy. Graefes Arch. Clin. Exp. Ophthalmol. 236, 207-212 (1998).
6. Kim, S. Y. et al. Morphometric analysis of the macula in eyes with geographic atrophy due to age-related macular degeneration. Retina 22, 464-470 (2002).

7. Holz, F. G., Bellman, C., Staudt, S., Schutt, F. \& Volcker, H. E. Fundus autofluorescence and development of geographic atrophy in age-related macular degeneration. Invest. Ophthalmol. Vis. Sci. 42, 1051-1056 (2001).

8. Sparrow, J. R. et al. A2E, a byproduct of the visual cycle. Vision Res. 43 2983-2990 (2003)

9. Liu, J., Itagaki, Y., Ben-Shabat, S., Nakanishi, K. \& Sparrow, J. R. The biosynthesis of $\mathrm{A} 2 \mathrm{E}$, a fluorophore of aging retina, involves the formation of the precursor, $\mathrm{A} 2-\mathrm{PE}$, in the photoreceptor outer segment membrane. J. Biol. Chem. 275, 29354-29360 (2000).

10. Sparrow, J. R., Zhou, J. \& Cai, B. DNA is a target of the photodynamic effects elicited in A2E-laden RPE by blue-light illumination. Invest. Ophthalmol. Vis. Sci. 44, 2245-2251 (2003).

11. Sparrow, J. R. \& Boulton, M. RPE lipofuscin and its role in retinal pathobiology. Exp. Eye Res. 80, 595-606 (2005)

12. Lopez-Otin, C., Blasco, M. A., Partridge, L., Serrano, M. \& Kroemer, G. The hallmarks of aging. Cell 153, 1194-1217 (2013).

13. Matsunaga, $\mathrm{H}$. et al. Beta-galactosidase histochemistry and telomere loss in senescent retinal pigment epithelial cells. Invest. Ophthalmol. Vis. Sci. 40 197-202 (1999).

14. Park, J. K., Kim, B. H., Han, Y. S. \& Park, I. K. The effect of telomerase expression on the escape from $M 2$ crisis in virus-transformed human retinal pigment epithelial cells. Exp. Mol. Med. 34, 107-113 (2002)

15. Gilson, E. \& Geli, V. How telomeres are replicated. Nat. Rev. Mol. Cell Biol. 8, 825-838 (2007).

16. Ye, J., Renault, V. M., Jamet, K. \& Gilson, E. Transcriptional outcome of telomere signalling. Nat. Rev. Genet. 15, 491-503 (2014).

17. Sparrow, J. R. et al. A2E-epoxides damage DNA in retinal pigment epithelia cells. Vitamin $\mathrm{E}$ and other antioxidants inhibit A2E-epoxide formation. J. Biol. Chem. 278, 18207-18213 (2003).

18. Sparrow, J. R., Parish, C. A., Hashimoto, M. \& Nakanishi, K. A2E, a lipofuscin fluorophore, in human retinal pigmented epithelial cells in culture. Invest. Ophthalmol. Vis. Sci. 40, 2988-2995 (1999).

19. Elbini, D. I. et al. A minireview on N-acetylcysteine: an old drug with new approaches. Life Sci. 151, 359-363 (2016).

20. Takai, H., Smogorzewska, A. \& de Lange, T. DNA damage foci at dysfunctional telomeres. Curr. Biol. 13, 1549-1556 (2003).

21. Shi, Q. et al. A2E suppresses regulatory function of RPE cells in Th1 cell differentiation via production of IL-1 beta and inhibition of PGE2. Invest. Ophthalmol. Vis. Sci. 56, 7728-7738 (2015)

22. Chien, $\mathrm{Y}$. et al. Control of the senescence-associated secretory phenotype by NF-kappaB promotes senescence and enhances chemosensitivity. Genes Dev. 25, 2125-2136 (2011).

23. Hoare, M. \& Narita, M. Transmitting senescence to the cell neighbourhood. Nat. Cell Biol. 15, 887-889 (2013).

24. Klein, R., Klein, B. E., Tomany, S. C., Meuer, S. M. \& Huang, G. H. Ten-year incidence and progression of age-related maculopathy: the Beaver Dam eye study. Ophthalmology 109, 1767-1779 (2002).

25. Klein, R. et al. Fifteen-year cumulative incidence of age-related macular degeneration: the Beaver Dam Eye Study. Ophthalmology 114, 253-262 (2007).

26. Harman, D. The aging process. Proc. Natl Acad. Sci. USA 78, 7124-7128 (1981)

27. Campisi, J. \& D'Adda, D. F. F. Cellular senescence: when bad things happen to good cells. Nat. Rev. Mol. Cell Biol. 8, 729-740 (2007).

28. Baker, D. J. et al. Naturally occurring p16(Ink4a)-positive cells shorten healthy lifespan. Nature 530, 184-189 (2016).

29. Jarrett, S. G., Lin, H., Godley, B. F. \& Boulton, M. E. Mitochondrial DNA damage and its potential role in retinal degeneration. Prog. Retin. Eye Res. 27, 596-607 (2008).

30. Lin, $H$. et al. Mitochondrial DNA damage and repair in RPE associated with aging and age-related macular degeneration. Invest. Ophthalmol. Vis. Sci. 52, 3521-3529 (2011)

31. Wang, A. L., Lukas, T. J., Yuan, M. \& Neufeld, A. H. Increased mitochondrial DNA damage and down-regulation of DNA repair enzymes in aged rodent retinal pigment epithelium and choroid. Mol. Vis. 14, 644-651 (2008).

32. Blasiak, J., Synowiec, E, Salminen, A. \& Kaarniranta, K. Genetic variability in DNA repair proteins in age-related macular degeneration. Int. J. Mol. Sci. 13, 13378-13397 (2012)

33. von Zglinicki, T. Oxidative stress shortens telomeres. Trends Biochem. Sci. 27, 339-344 (2002) 
34. Kuilman, T. \& Peeper, D. S. Senescence-messaging secretome: SMS-ing cellular stress. Nat. Rev. Cancer 9, 81-94 (2009).

35. Krtolica, A., Parrinello, S., Lockett, S., Desprez, P. Y. \& Campisi, J. Senescent fibroblasts promote epithelial cell growth and tumorigenesis: a link between cancer and aging. Proc. Natl Acad. Sci. USA 98, 12072-12077 (2001).

36. Krizhanovsky, V. et al. Senescence of activated stellate cells limits liver fibrosis. Cell 134, 657-667 (2008)

37. Demaria, M. et al. An essential role for senescent cells in optimal wound healing through secretion of PDGF-AA. Dev. Cell 31, 722-733 (2014).

38. Goverdhan, S. V. et al. Interleukin-8 promoter polymorphism $-251 \mathrm{~A} / \mathrm{T}$ is a risk factor for age-related macular degeneration. Br. J. Ophthalmol. 92, 537-540 (2008).

39. Andriani, G. A. et al. Whole Chromosome Instability induces senescence and promotes SASP. Sci. Rep. 6, 35218 (2016).

40. Bian, Q. et al. Lutein and zeaxanthin supplementation reduces photooxidative damage and modulates the expression of inflammation-related genes in retinal pigment epithelial cells. Free Radic. Biol. Med. 53, 1298-1307 (2012).

41. Zhang, J. et al. Protective effect of autophagy on human retinal pigment epithelial cells against lipofuscin fluorophore A2E: implications for age-related macular degeneration. Cell Death Dis. 6, e1972 (2015).
42. Bernardes, D. J. B. \& Blasco, M. A. Potential of telomerase activation in extending health span and longevity. Curr. Opin. Cell Biol. 24, 739-743 (2012).

43. Parish, C. A., Hashimoto, M., Nakanishi, K., Dillon, J. \& Sparrow, J. Isolation and one-step preparation of $\mathrm{A} 2 \mathrm{E}$ and iso-A2E, fluorophores from human retinal pigment epithelium. Proc. Natl Acad. Sci. USA 95, 14609-14613 (1998).

44. Feng, J., Chen, X., Sun, X., Wang, F. \& Sun, X. Expression of endoplasmic reticulum stress markers GRP78 and CHOP induced by oxidative stress in blue light-mediated damage of A2E-containing retinal pigment epithelium cells. Ophthalmic Res. 52, 224-233 (2014)

45. Cawthon, R. M. Telomere measurement by quantitative PCR. Nucleic Acids Res. 30, e47 (2002)

46. Misenko, S.M. \& Bunting, S. F. Rapid analysis of chromosome aberrations in mouse B lymphocytes by PNA-FISH. J. Vis. Exp. 90 (2014).

47. Guo, R. et al. BS69/ZMYND11 reads and connects histone H3.3 lysine 36 trimethylation-decorated chromatin to regulated pre-mRNA processing. Mol. Cell 56, 298-310 (2014).

48. Trapnell, C. et al. Differential gene and transcript expression analysis of RNA-seq experiments with TopHat and Cufflinks. Nat. Protoc. 7, 562-567 (2012). 